\title{
High-quality single crystal growth of Bi-based perovskite ferroelectrics based on defect chemistry
}

\author{
Yuji NOGUCHI, ${ }^{\dagger}$ Ichiro TANABE, Muneyasu SUZUKI and Masaru MIYAYAMA
}

Research Center for Advanced Science and Technology, The University of Tokyo, 4-6-1, Komaba, Meguro-ku, Tokyo 153-8904

\begin{abstract}
We present the $\mathrm{O}_{2}$-blowing method for the growth of high-quality single crystals of Bi-based perovskite ferroelectrics, in which $\mathrm{O}_{2}$ gas is directly introduced inside crucibles during crystal growth. The $\mathrm{O}_{2}$-blowing method is demonstrated to be effective for enhancing polarization and piezoelectric properties as well as reducing leakage current for $(\mathrm{Bi}, \mathrm{Na}) \mathrm{TiO}_{3}-\mathrm{BaTiO}_{3}$ crystals. $\mathrm{The}^{-}$ superior properties are suggested to originate from the reduced reorientation of non- $180^{\circ}$ domains. $A b$ initio calculations suggest that the interaction between spontaneous polarization and defect dipole composed of Bi vacancy and $O$ vacancy is the origin of the reorientation of non- $180^{\circ}$ domains.
\end{abstract}

(C2008 The Ceramic Society of Japan. All rights reserved.

\section{Introduction}

In view of a worsening global environment posing serious problems, the environmental preservation of the earth and symbiosis with nature are the primary purpose of our industrial activities. Perovskite ferroelectric $\mathrm{Pb}(\mathrm{Zr}, \mathrm{Ti}) \mathrm{O}_{3}$ and related $\mathrm{Pb}$-based materials including toxic lead have been used exclusively as the active material of sensors, transducers, actuators and non-volatile memories. ${ }^{1)-17)}$ Since the use of $\mathrm{Pb}(\mathrm{Zr}, \mathrm{Ti}) \mathrm{O}_{3}$ in electronic materials would be restricted in the near future, the development of lead-free ferroelectric materials with sufficient ferroelectric and piezoelectric properties has been strongly demanded from the environmental and economical points of view. In recent days, lead-free perovskite ferroelectrics of $\left.\mathrm{BaTiO}_{3}(\mathrm{BT}),{ }^{18)-23}\right)(\mathrm{Bi}, \mathrm{K}$, $\mathrm{Na}) \mathrm{TiO}_{3},{ }^{24)-32)}(\mathrm{K}, \mathrm{Na}) \mathrm{NbO}_{3}(\mathrm{KNN})^{33)-39)}$ and layered ferroelectrics of $\mathrm{SrBi}_{2} \mathrm{Ta}_{2} \mathrm{O}_{9},{ }^{40)-47)} \mathrm{Bi}_{4} \mathrm{Ti}_{3} \mathrm{O}_{12}(\mathrm{BiT}),{ }^{48)-55)} \mathrm{CaBi}_{4} \mathrm{Ti}_{4} \mathrm{O}_{15}{ }^{56)-62}$ and their derivatives ${ }^{63)}$ have attracted much attention as alternative materials of $\mathrm{Pb}(\mathrm{Zr}, \mathrm{Ti}) \mathrm{O}_{3}$.

Potassium sodium niobate $(\mathrm{KNN})^{33-35)}$ has been regarded as a promising lead-free piezoelectric material, because of its high Curie temperature $\left(T_{\mathrm{C}}\right)$ of $420^{\circ} \mathrm{C}$ and superior piezoelectric properties. KNN shows a consecutive structural phase transition from cubic to tetragonal around $420^{\circ} \mathrm{C}$ and tetragonal to orthorhombic around $200^{\circ} \mathrm{C}$. Although piezoelectric properties are markedly enhanced by the presence of tetragonal-orthorhombic phase transition, ${ }^{33), 34)}$ the temperature dependence of materialsproperties near the transition temperature becomes extremely high. ${ }^{64)}$ The superior properties near phase-transition temperature are tricky to use for practical applications, in which temperature stability of the materials properties are strongly demanded in a wide range of temperature from -50 to $120^{\circ} \mathrm{C}$. Recently, this problems related to the tetragonal-orthorhombic phase transition of KNN have been overcome by doping technique. ${ }^{64)}$ Nevertheless, the expensiveness of $\mathrm{Nb}$ is still considered a barrier for the bulk applications of KNN-based devices.

Ti-based perovskite ferroelectrics such as $\mathrm{BT}^{18)-23)}$ and

Corresponding author: Y. Noguchi; E-mail: ynoguchi@crm.rcast. u-tokyo.ac.jp
$(\mathrm{Bi}, \mathrm{Na}, \mathrm{K}) \mathrm{TiO}_{3}{ }^{24)-32}$ have recognized as cost-effective lead-free piezoelectric materials. Recent investigations ${ }^{18), 22), 23)}$ have demonstrate that fine-grained BT ceramics with a grain size of $\sim 100$ nm show a large piezoelectric strain constant $d_{33}$, in which engineered domain configurations ${ }^{22,23)}$ probably enhance the piezoelectric properties. However, $T_{\mathrm{C}}$ of $\mathrm{BT}$ is as low as $135^{\circ} \mathrm{C}$, and furthermore fine-grained BT ceramics exhibit a tetragonalorthorhombic transition temperature around room temperature. ${ }^{19)}$ These phase transitions constitute an obstacle to the practical applications of BT.

Pioneering works by Takenaka et al. ${ }^{24)-26)}$ have shown that $(\mathrm{Bi}, \mathrm{Na}) \mathrm{TiO}_{3}(\mathrm{BNT})$ is an attractive piezoelectric material because of a high $T_{\mathrm{C}}$ of $320^{\circ} \mathrm{C}$ and a large spontaneous polarization. One of the problems to be overcome is that depolarization temperature $\left(T_{\mathrm{d}}\right)$, i.e., piezoelectric activities disappear or are markedly reduced at $T_{\mathrm{d}}$, lies around $200^{\circ} \mathrm{C}$ for $\mathrm{BNT}^{65)-68)}$ for BNT due to structural phase transition from rhombohedral ( $R 3 c$ symmetry: ferroelectric) to tetragonal ( $P 4 \mathrm{bm}$ symmetry: weak ferroelectric). ${ }^{67), 68)}$ It is widely accepted that the use of BNT-based ferroelectrics for piezoelectric materials opens up the possibility of lead-free piezoelectric devices in views of properties and costeffectiveness.

It is well known that rhombohedral BNT constitutes a morphotropic phase boundary (MPB) with tetragonal BT. The piezoelectric properties have been enhanced for the ceramics of BNT-BT solid solutions near the MPB composition. ${ }^{26)}$ Although BNT-BT ceramics near the MPB composition have been intensively studied, marked enhancement in piezoelectric properties has not been achieved to date as well as the reported values of the piezoelectric constants etc. are scattered, ${ }^{26), 69)-79)}$ which seems to be ascribed to the multiple influences of microstructure, grain size and orientation, nonstoichiometry, and defects.

Defects in ferroelectric materials play an important role in their properties of leakage current, ferroelectric and piezoelectric proprieties. The control of polarization states is the underlying basis of ferroelectric and piezoelectric devices. Polarization switching is achieved through nucleation of domains and subsequent domain-wall motion by applying an electric field $(E)$. Leakage current arising from defects, however, interferes with 
the polarization switching of Bi-based perovskites. ${ }^{80)-83)}$ In addition, oxygen vacancies are known to act as an obstacle to the polarization switching, ${ }^{84)-86)}$ and a resultant remanent polarization $\left(P_{\mathrm{r}}\right)$ is suppressed by the clamping of the domain walls by oxygen vacancies. The leakage current and domain clamping by oxygen vacancies make ferroelectric materials unsuitable for practical applications. ${ }^{42), 87)-95)}$ Thus, a guiding principle of defect control is required to be established for obtaining high-quality Bi-based devices with superior piezoelectric properties. Investigations on single crystals seem advantageous to know the influences of defects on the properties of ferroelectric materials, in which microstructure and grain size does not affect the properties.

In this study, the single crystals of BNT-BT near the MPB composition (91\%BNT-9\%BT) is selected as a model material for Bi-based ferroelectrics, and the defect chemistry during crystal growth is investigated to obtain a materials processing leading to high-quality Bi-based perovskite ferroelectrics. The $\mathrm{O}_{2}$-blowing method, ${ }^{96), 97)}$ in which $\mathrm{O}_{2}$ gas is introduced directly to the melt surface in crucible during crystal growth, is demonstrated to be effective for obtaining high-quality BNT-BT crystals with superior piezoelectric properties. The blowing of $\mathrm{O}_{2}$ gas during crystal growth suppresses the defect formation reaction leading to Bi vacancy and oxygen vacancy, which is the origin of the enhanced piezoelectric properties for the high-quality BNT-BT crystals.

\section{Experiments and $a b$ initio electronic calculations}

Single crystals of BNT-BT were grown by the $\mathrm{O}_{2}$-blowing method based on high-temperature flux technique. ${ }^{98)}$ The schematic image of the furnace used in this study is illustrated in Fig. 1(a). Pt crucibles with $30 \mathrm{cc}$ were used, and the crucible was covered with alumina lid at the center of which the hole with $6.2 \mathrm{~mm}$ diameter was present. Alumina tube with an inner diameter of 4 $\mathrm{mm}$ (wall thickness of $1 \mathrm{~mm}$ ) was placed in the hole of the alumina lid for $\mathrm{O}_{2}$ blowing, and $\mathrm{O}_{2}$ gas was introduced through the alumina tube to the melt surface. The distance between the melt surface and the forefront of the alumina tube was critical for crystal growth. This distance was fixed at $1 \mathrm{~mm}$ in our experiments.

High purity powders of $\mathrm{Bi}_{2} \mathrm{O}_{3}(99.9999 \%), \quad \mathrm{Na}_{2} \mathrm{CO}_{3}$ (99.999\%), $\mathrm{BaCO}_{3}(99.99 \%)$ and $\mathrm{TiO}_{2}(99.99 \%)$ were used as raw materials. The mixed powders with the composition of $0.88 \mathrm{BNT}-0.12 \mathrm{BT}$ were calcined at $850^{\circ} \mathrm{C}$ for $4 \mathrm{~h}$ in air, which led to single-phase powder with perovskite structure. 0.88BNT0.12BT powder mixed with $\mathrm{Bi}_{2} \mathrm{O}_{3}$ and $\mathrm{NaF}$ as fluxes were soaked at $1300^{\circ} \mathrm{C}$ for $5 \mathrm{~h}$ in the $\mathrm{Pt}$ crucible. The profiles of temperature and $\mathrm{O}_{2}$-flow rate during crystal growth are illustrated in Fig. 1 (b). For the last $1 \mathrm{~h}$ during the soaking, the flow rate of $\mathrm{O}_{2}$ gas increased linearly from zero to a certain value $(50 \mathrm{ml} / \mathrm{min}, 100$ $\mathrm{ml} / \mathrm{min}$ and $150 \mathrm{ml} / \mathrm{min}$ ). The temperature decrease at the melt surface by the blowing of $\mathrm{O}_{2}$ was about $30^{\circ} \mathrm{C}(50 \mathrm{ml} / \mathrm{min}), 70^{\circ} \mathrm{C}$ $(100 \mathrm{ml} / \mathrm{min})$ and $110^{\circ} \mathrm{C}(150 \mathrm{ml} / \mathrm{min})$. The blowing of $\mathrm{O}_{2}$ to the melt surface was kept at the flow rate described above during crystal growth. The temperature of the furnace was slowly cooled from $1300^{\circ} \mathrm{C}$ to $1100^{\circ} \mathrm{C}$ for $10 \mathrm{~h}$ with the $\mathrm{O}_{2}$ blowing. Single crystals of BNT-BT with a maximum size of $5 \times 5 \times 3$ $\mathrm{mm}^{3}$ were obtained just beneath the alumina tube and smallsized crystals $\left(2 \times 2 \times 2 \mathrm{~mm}^{3}\right)$ were present at around the edge of the crucible (Fig. 1(c)). When the flow rate of $\mathrm{O}_{2}$ increased to $200 \mathrm{ml} / \mathrm{min}$, the melt surface was rippling and then crystals were not obtained. The crystals were annealed at $950^{\circ} \mathrm{C}$ for $10 \mathrm{~h}$ in air
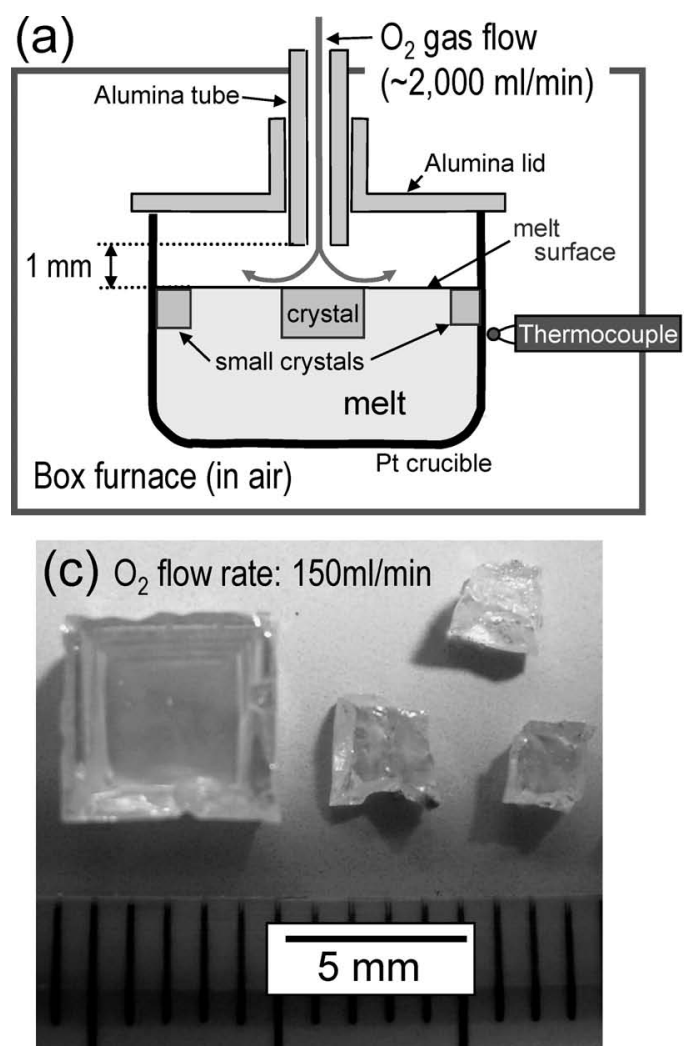

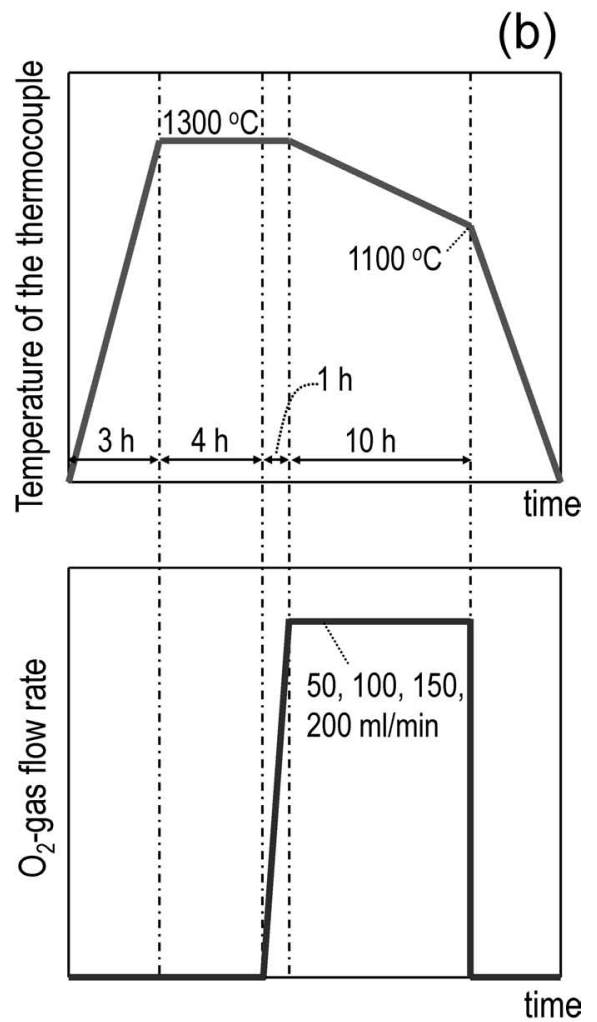

Fig. 1. (a) Electric furnace used for the crystal growth based on the $\mathrm{O}_{2}$-blowing method, (b) the profiles of temperature and $\mathrm{O}_{2-}$ flow rate during crystal growth and (c) the crystals obtained by the $\mathrm{O}_{2}$-blowing method with a flow rate of $150 \mathrm{ml} / \mathrm{min}$. 
before electrical measurements. The chemical composition of the crystals determined by inductively coupled plasma atomic emission spectrometry was $0.91 \mathrm{BNT}-0.09 \mathrm{BT}$, which did not depend on the $\mathrm{O}_{2}$ flow rate during crystal growth. The composition of $\mathrm{BT}$ of the crystals was smaller than that of the starting powder (0.88BNT-0.12BT)

For electric characterizations, the crystals were sliced parallel to $(001)_{\text {cubic }}$ into plates $250 \mu \mathrm{m}$ in thickness and gold electrodes were sputtered on both sides of the specimens. Polarization $(P)-$ electric field $(E)$ hysteresis loops and $E$-induced strains $(S)$ at a frequency of $0.5 \mathrm{~Hz}$ were measured using a ferroelectric test system (Toyo Corporation; Model $6252 \mathrm{Rev}$. B) at $25^{\circ} \mathrm{C}$.

In order to obtain an insight into the interaction between $P_{\mathrm{s}}$ and defect dipole, $a b$ initio density functional theory (DFT) $)^{99), 100)}$ calculations of tetragonal $\mathrm{BaTiO}_{3}$ were conducted within the generalized gradient approximation (GGA-PBE) ${ }^{101), 102)}$ using the all-electron projector augmented wave (PAW) method ${ }^{103}$ implemented in VASP. ${ }^{104), 105)}$ As a model material of perovskite ferroelectric oxide with a tetragonal $P 4 \mathrm{~mm}$ structure, we selected tetragonal $\mathrm{BaTiO}_{3}$ to calculate the total energies of the crystals with different defect dipole configurations. We created a $2 \times 2 \times$ 3 supercell using the optimized tetragonal $\mathrm{BaTiO}_{3}$ unit cell, and then generated the vacancies of $\mathrm{Ba}$ and $\mathrm{O}$. After relaxing the lattice parameters and the fractional coordinates of all atoms of the supercell with defect dipole $\left(D_{\mathrm{A}-\mathrm{O}}\right)$ composed of $A$-site $(\mathrm{Ba})$ vacancy and $\mathrm{O}$ vacancy, the total energies were compared in order to investigate a stable configuration of $D_{\mathrm{A}-\mathrm{O}}$ with $P_{\mathrm{s}}$. A cutoff kinetic energy was set as $400 \mathrm{eV}$ throughout the calculations.

\section{Results}

Figure 2 shows the leakage current density $(J)$ at $25^{\circ} \mathrm{C}$ as a

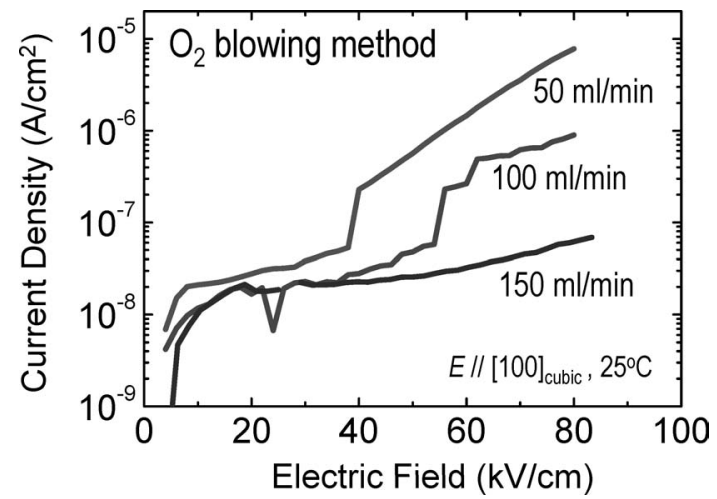

Fig. 2. Leakage current density as a function of applied electric field along the $[100]_{\text {cubic }}$ direction measured at $25^{\circ} \mathrm{C}$.
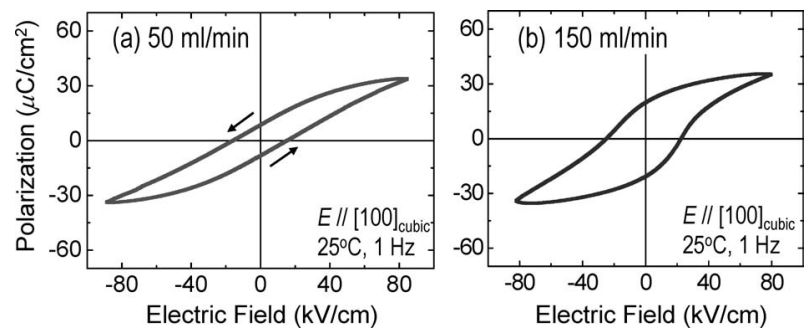

Fig. 3. Polarization hysteresis loops measured along the $[100]_{\text {cubic }}$ direction at $25^{\circ} \mathrm{C}(1 \mathrm{~Hz})$. function of $E$ applied along the [100] $]_{\text {cubic }}$ direction. Hereafter, cubic notation is used for describing crystal orientation throughout the manuscript. The value of $J$ in the low $E$ region below $40 \mathrm{kV} / \mathrm{cm}$ was almost the same for all the crystals with different $\mathrm{O}_{2}$ flow rate, while $J$ in the higher $E$ region decreased markedly with increasing $\mathrm{O}_{2}$ flow rate. At an $E$ of $80 \mathrm{kV} / \mathrm{cm}$, the crystals (50 $\mathrm{ml} / \mathrm{min}$ ) showed a high $J$ of $10^{-5} \mathrm{~A} / \mathrm{cm}^{2}$. It is interesting to note that the crystals $(150 \mathrm{ml} / \mathrm{min})$ exhibited a $J$ of $\sim 10^{-7} \mathrm{~A} / \mathrm{cm}^{2}$, which was by about two orders of magnitude lower than those of the crystals $(50 \mathrm{ml} / \mathrm{min}$ ). When Pt electrodes were used for the measurements, a significant change in $J$ was not observed. These results demonstrate that the leakage current properties for BNTBT crystals obtained in this study are not influenced by the interface between the electrodes and the ferroelectrics but determined by defects inside the crystals.

Figure 3 indicates the $P-E$ hysteresis loop measured along the [100 $]_{\text {cubic }}$ direction at $25^{\circ} \mathrm{C}$. The crystals $(50 \mathrm{ml} / \mathrm{min})$ showed a small hysteresis with a $P_{\mathrm{r}}$ of $8 \mu \mathrm{C} / \mathrm{cm}^{2}$. This small $P_{\mathrm{r}}$ seems to be attributed to domain reorientation ${ }^{11), 106), 107)}$ with decreasing $E$, as discussed below. Polarization properties were drastically improved with increasing $\mathrm{O}_{2}$ flow rate during crystal growth, and the $P_{\mathrm{r}}$ value of the crystals $(150 \mathrm{ml} / \mathrm{min})$ was as large as $20 \mu \mathrm{C} /$ $\mathrm{cm}^{2}$. The crystals $(100 \mathrm{ml} / \mathrm{min})$ had a $P_{\mathrm{r}}$ of $10 \mu \mathrm{C} / \mathrm{cm}^{2}$. The polarization and leakage current properties are summarized in Table 1.

Figure 4 shows the $S$ induced by $E$ application measured along the $[100]_{\text {cubic }}$ direction at $25^{\circ} \mathrm{C}$. Before measurements, a unipolar $E$ of $60-80 \mathrm{kV} / \mathrm{cm}$ was applied to the crystals at $25^{\circ} \mathrm{C}$ several times for electrical poling. For the crystals $(50 \mathrm{ml} / \mathrm{min})$, $S$ gradually increased with increasing $E$ in the low $E$ region below $20 \mathrm{kV} / \mathrm{cm}$, which was due to their small piezoelectric

Table 1. Polarization and Piezoelectric Properties of 0.91BNT0.09BT Crystals Grown by the $\mathrm{O}_{2}$ Blowing Method

\begin{tabular}{cccc}
\hline $\begin{array}{c}\mathrm{O}_{2} \text { flow rate } \\
\text { during crystal growth }\end{array}$ & $50 \mathrm{ml} / \mathrm{min}$ & $100 \mathrm{ml} / \mathrm{min}$ & $150 \mathrm{ml} / \mathrm{min}$ \\
\hline$P_{\mathrm{r}}\left(\mu \mathrm{C} / \mathrm{cm}^{2}\right)$ & 8 & 10 & 20 \\
\hline $\begin{array}{c}\text { Leakage current density } \\
\left(\mathrm{A} / \mathrm{cm}^{2}\right) \text { at } 80 \mathrm{kV} / \mathrm{cm}\end{array}$ & $7.8 \times 10^{-6}$ & $9 . \times 10^{-7}$ & $6.9 \times 10^{-8}$ \\
\hline$S_{\max } / E_{\max }(\mathrm{pm} / \mathrm{V})$ & 337 & 295 & 368 \\
\hline $\begin{array}{c}\text { Dominant contribution to } \\
E \text {-induced strain }\end{array}$ & $\begin{array}{c}\text { non- } 180^{\circ} \\
\text { domain } \\
\text { rotation }\end{array}$ & $\begin{array}{c}\text { non-180 } \\
\text { domain } \\
\text { rotation }\end{array}$ & $\begin{array}{c}\text { inverse } \\
\text { piezoelectric } \\
\text { effect }\end{array}$ \\
\hline $\begin{array}{c}\text { Piezoelectric strain } \\
\text { constant }{ }^{\mathrm{a}} d_{33}(\mathrm{pm} / \mathrm{V})\end{array}$ & 6 & 66 & 242 \\
\hline${ }^{\mathrm{a}}$ The value of $d_{33} \mathrm{Was}$ determined by the slope in the $S-E$ curve below $E$ \\
$=10 \mathrm{kV} / \mathrm{cm}$.
\end{tabular}
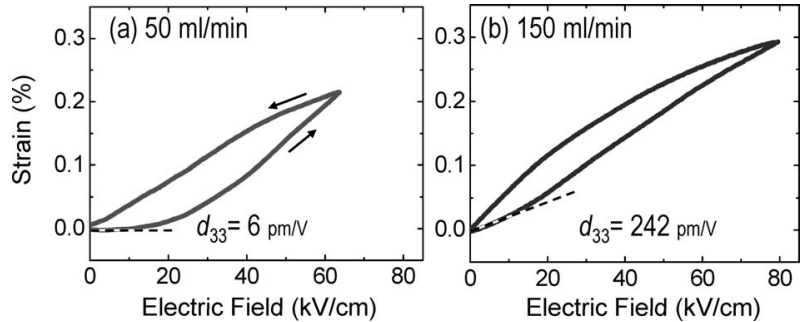

Fig. 4. Strain curves induced by applying an electric field measured along the $[100]_{\text {cubic }}$ direction at $25^{\circ} \mathrm{C}(1 \mathrm{~Hz})$. 
strain constant $\left(d_{33}\right)$. The value of $d_{33}$ determined by the slope below $10 \mathrm{kV} / \mathrm{cm}$ was $6 \mathrm{pm} / \mathrm{V}$ for the crystals $(50 \mathrm{ml} / \mathrm{min})$. Above $E$ of $20 \mathrm{kV} / \mathrm{cm}, S$ showed a quadratic increase with $E$, which does not originate from inverse piezoelectric effects but probably from the rotation of non- $180^{\circ}$ domains ${ }^{11), 106), 107)}$ induced by $E$ application. An $E$ application over $70 \mathrm{kV} / \mathrm{cm}$ led to a dielectric breakdown of the crystals $(50 \mathrm{ml} / \mathrm{min})$. A strain constant defined by $S_{\max } / E_{\max }$ was $337 \mathrm{pm} / \mathrm{V}$ for the crystals $(50 \mathrm{ml} / \mathrm{min})$. The value of $S$ during $E$ decreasing was larger than that during $E$ increasing at the same $E$ value, and $S$ became almost zero at $E$ $=0 \mathrm{kV} / \mathrm{cm}$. The hysteresis in the $S-E$ curve has been reported to originate from the reorientation of non- $180^{\circ}$ domain due to defects, ${ }^{106), 107)}$ as discussed below. Almost the same $S-E$ properties with difference strain constants were observed for the crystals $(100 \mathrm{ml} / \mathrm{min})$, which showed a $d_{33}$ of $14 \mathrm{pm} / \mathrm{V}$ and an $S_{\max } /$ $E_{\max }$ of $295 \mathrm{pm} / \mathrm{V}$. These strain data are also listed in Table 1.

It is noteworthy that the crystals $(150 \mathrm{ml} / \mathrm{min})$ showed a liner increase in $S$ with $E$ even in the low $E$ region. The $d_{33}$ value estimated from the slope below $10 \mathrm{kV} / \mathrm{cm}$ was $242 \mathrm{pm} / \mathrm{V}$, which was 20 times as large as that of the crystals $(100 \mathrm{ml} / \mathrm{min})$. The $S-E$ curve of the crystals $(150 \mathrm{ml} / \mathrm{min})$ was similar to those of $\mathrm{Pb}(\mathrm{Zr}, \mathrm{Ti}) \mathrm{O}_{3}$ ceramics, ${ }^{11)}$ and the strain behavior is mainly ascribed to inverse piezoelectric effects. The $S_{\max } / E_{\max }$ value of the crystals $(150 \mathrm{ml} / \mathrm{min})$ was $368 \mathrm{pm} / \mathrm{V}$.

\section{Discussion}

\subsection{Defect formation at high temperatures}

We consider the effects of the $\mathrm{O}_{2}$ blowing to the melt surface during crystal growth. Since the $\mathrm{O}_{2}$ blowing decreases the temperature just beneath the forefront of the alumina tube by some degree, the process of crystal growth is influenced by the $\mathrm{O}_{2}$ blowing. In fact, the $\mathrm{O}_{2}$ blowing method provides larger single crystals of BNT-BT. It is, however, apparent that the properties shown in Figs. 2-4 are not directly related to the size of the crystals. Here, defects which strongly affect the electrical properties are focused.

At high temperatures, elements with a high vapor pressure such as Bi are apt to evaporate from the surface of solid as well as liquid. BNT-BT crystals are floating in the melt (see Fig. 1(a)) due to the low specific gravity of BNT-BT compared with the melt, and the crystals are obtained from the upper part of the flux. Therefore, the evaporation of Bi from the crystal surface at high temperatures plays a critical role in the properties at room temperature of the resultant crystals. It has been reported for $\mathrm{Bi}$ based layered ferroelectric of $\mathrm{Bi}_{4} \mathrm{Ti}_{3} \mathrm{O}_{12}$ that the trigger of defect formation is the generation of $\mathrm{Bi}$ vacancy $\left(V_{\mathrm{Bi}}\right.$ "'), which is accompanied by the formation of oxygen vacancy $\left(V_{\mathrm{O}}{ }^{*}\right)$ due to charge compensation. ${ }^{89), 95), 108)}$ The vacancy formation at high temperatures is expressed by

$$
2 \mathrm{Bi}_{\mathrm{Bi}}{ }^{\times}+3 \mathrm{O}_{\mathrm{O}}{ }^{\times} \rightarrow 2 V_{\mathrm{Bi}}{ }^{\prime}{ }^{\prime}+3 V_{\mathrm{O}}{ }^{*}+2 \mathrm{Bi} \text { (gas) }+3 / 2 \mathrm{O}_{2} \text { (gas), }
$$

where $\mathrm{Bi}_{\mathrm{Bi}}{ }^{\times}$is $\mathrm{Bi}^{3+}$ (lattice) at the $\mathrm{Bi}$ site and $\mathrm{O}_{\mathrm{O}}{ }^{\times}$denotes $\mathrm{O}^{2-}$ (lattice) at the $\mathrm{O}$ site. Noguchi et al. ${ }^{108), 109)}$ have indicated that the vacancy formation of $\mathrm{Bi}$ proceeds preferentially in the perovskite layers rather than in the $\mathrm{Bi}_{2} \mathrm{O}_{2}$ layers. The reaction of the vacancy formation (Eq. (1)) has been reported to occur above $1000^{\circ} \mathrm{C}$ in air. $^{108), 109)}$

It is interesting to note that the weight loss due to the formation of $V_{\mathrm{Bi}}$ " " and $V_{\mathrm{O}}{ }^{\circ}$ at high temperatures are reduced under a higher $\mathrm{PO}_{2}$ atmosphere. ${ }^{108), 109)}$ The $P_{\mathrm{O}_{2}}$ dependence of weight loss demonstrates that the limiting factor of the vacancy formation is not diffusion of the vacancies inside the crystals but surface reaction on the crystal surface. The following model of the vacancy formation of Bi-based perovskite oxides (Fig. 5) is proposed. ${ }^{108), 109)}$ Two $\mathrm{Bi}_{\mathrm{Bi}}{ }^{\times}$and three $\mathrm{O}_{\mathrm{O}}{ }^{\times}$migrate to the surface of crystals, but do not react with each other because of the low possibility of $\mathrm{Bi}_{\mathrm{ad}}$ to meet $\mathrm{O}_{\mathrm{ad}}$ on the surface, where $\mathrm{Bi}_{\mathrm{ad}}$ and $\mathrm{O}_{\mathrm{ad}}$ are adsorbed $\mathrm{Bi}$ and $\mathrm{O}$ on the surface. $\mathrm{Bi}_{\mathrm{ad}}$ detaches from the surface as $\mathrm{Bi}$ (gas) and then $\mathrm{Bi}$ (gas) promptly reacts with $\mathrm{O}_{2}$ (gas) to form $\mathrm{Bi}_{2} \mathrm{O}_{3}$ (gas) in the atmosphere, as expressed by the following equations;

$$
\begin{aligned}
& \mathrm{Bi}_{\mathrm{ad}} \rightarrow \mathrm{Bi}(\text { gas }), \\
& 2 \mathrm{Bi}(\text { gas })+3 / 2 \mathrm{O}_{2} \rightarrow \mathrm{Bi}_{2} \mathrm{O}_{3} \text { (gas). }
\end{aligned}
$$

These reactions proceed quickly and do not limit the vacancy formation of Eq. (1). In contrast, $\mathrm{O}_{\mathrm{ad}}$ has to meet another $\mathrm{O}_{\mathrm{ad}}$ on the surface to form an $\mathrm{O}_{2}$ molecule. The reaction related to $\mathrm{O}_{\mathrm{ad}}$ that is suppressed at a higher $\mathrm{PO}_{2}$ is the limiting factor of the vacancy formation as follows:

$$
2 \mathrm{O}_{\mathrm{ad}} \rightarrow \mathrm{O}_{2} \text { (gas) : rate-limiting reaction. }
$$

Therefore, the defect formation of Eq. (1) is suppressed under higher- $\mathrm{PO}_{2}$ atmosphere, because the equilibrium point of Eq. (4) moves to the left side, i.e., the rate-limiting reaction is prevented at a higher $\mathrm{PO}_{2}$. The defect formation during crystal growth is sensitive to $\mathrm{PO}_{2}$ just above the crystals inside the Pt crucible. Under low $\mathrm{PO}_{2}$ atmosphere, the defect formation of Eq. (1) is easy to proceed, and then low-quality crystals with high concentrations of $V_{\mathrm{Bi}}$ "' and $V_{\mathrm{O}}$ " are grown (Fig. 6(a)).

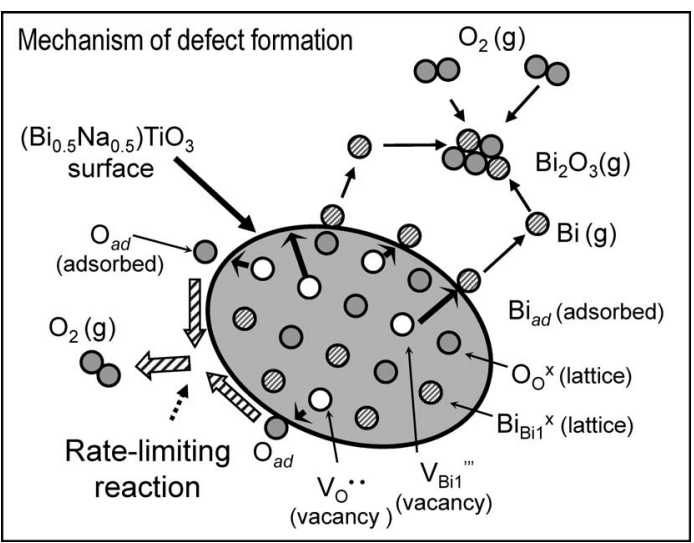

Fig. 5. Defect formation at high temperatures of BNT-BT crystals. The reaction related to $\mathrm{Bi}$ rapidly proceeds, while the transformation from adhesive $\mathrm{O}\left(\mathrm{O}_{\mathrm{ad}}\right)$ on the crystal surface to $\mathrm{O}_{2}$ (gas) is the rate-limiting reaction for the overall defect formation.

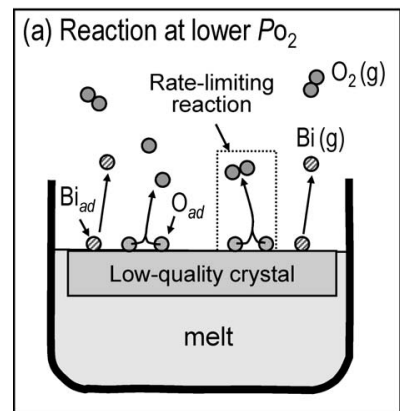

(b) Reaction at higher $\mathrm{PO}_{2}$

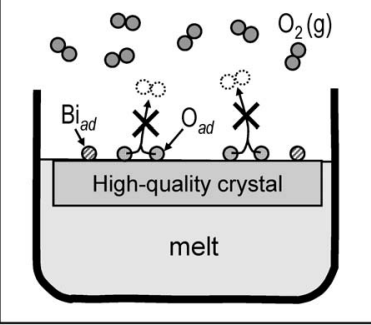

Fig. 6. Schematic images of the defect-formation reactions at (a) lower $\mathrm{PO}_{2}$ and (b) higher $\mathrm{PO}_{2}$ 
For the $\mathrm{O}_{2}$-blowing method, fresh $\mathrm{O}_{2}$ gas is introduced directly inside the crucible, and a high $P_{\mathrm{O}_{2}}$ is maintained even at the crystal surface (Fig. 6(b)). The higher $\mathrm{PO}_{2}$ atmosphere prevents the progress of the rate-limiting reaction of Eq. (4), and then the overall defect formation of Eq. (1) is suppressed. The $\mathrm{O}_{2-}$ blowing method is an effective technique for obtaining highquality Bi-based perovskite crystals with the low concentrations of $V_{\mathrm{Bi}} "$ and $V_{\mathrm{O}} \cdot$.

\subsection{Effects of $\mathrm{O}_{2}$ blowing during crystal growth on the leakage current properties}

The dependence of $\mathrm{O}_{2}$-flow rate on the leakage current properties (Fig. 2) can be explained by $\left[V_{O}{ }^{*}\right]$ in the crystals, where brackets indicate concentration. During cooling or annealing process below $1000^{\circ} \mathrm{C}$, in which the vacancy formation of Eq. (1) does not occur, the crystals absorb oxygen from ambient and the following oxidation reaction produces electron hole $\left(h^{*}\right)$ as follows:

$$
1 / 2 \mathrm{O}_{2}+V_{\mathrm{O}} \cdot \mathrm{O}_{\mathrm{O}}{ }^{\times}+2 h^{\bullet}
$$

The carrier of the leakage current for BNT crystals has been reported to be $h$ generated by the oxidation reaction (Eq. (5))..$^{98)}$ As discussed above, the crystals grown at a lower $P_{\mathrm{O}_{2}}$ have a higher $\left[V_{O} *\right]$, because the vacancy formation of Eq. (1) is accelerated under a lower $\mathrm{PO}_{2}$ atmosphere. Thus, the crystals $(150 \mathrm{ml} /$ $\min )$ with a lower $\left[V_{\mathrm{O}}{ }^{*}\right]$ have a lower $\left[h^{*}\right]$, leading to a lower $J$ than other crystals.

\subsection{Reorientation of domain structure leading to poor properties}

We discuss the reasons of the poor polarization and piezoelectric properties observed for the crystals with lower $\mathrm{O}_{2}$-flow rates. The properties of $P$ and $S$ are governed by domain dynamics induced by $E$ application. Here, tetragonal crystals with $P 4 \mathrm{~mm}$ symmetry are assumed for simplicity. In these crystals, two kinds of domain wall are present: one is $180^{\circ}$ domain wall across which $P_{\mathrm{s}}$ are antiparallel and the other is $90^{\circ}$ domain wall across which $P_{\mathrm{s}}$ rotates by about $90^{\circ} .180^{\circ}$ domains can be easily switched by $E$ application compared with $90^{\circ}$ domains and the volume of the backswitched $180^{\circ}$ domains is small. ${ }^{95)}$ In contrast, $90^{\circ}$ domains play a dominant role in the values of $P_{\mathrm{r}}$ and $d_{33}$, as a result of the reorientation of $90^{\circ}$ domain configurations in BNT-BT crystals (see Fig. 7). The crystal structure shown in Figs. 7 and $\mathbf{8}$ are drown by using the program VESTA (Visualization for Electronic and STructural Analysis) developed by Momma and Izumi (Ref. 110).

The polarization measurements show that the value of $P$ at $E$ $=80 \mathrm{kV} / \mathrm{cm}$ was almost the same for both the crystals $(50 \mathrm{ml} /$ min and $150 \mathrm{ml} / \mathrm{min}$ ) (Fig. 3). These results demonstrate that the rotation of $90^{\circ}$ domains is induced, i.e., almost the single domain state (Fig. 7(b)) is established by $E$ application. With decreasing $E$, the reorientation of the $90^{\circ}$ domains, i.e., the rotation of the domains by $90^{\circ}$, gradually takes place and finally initial $90^{\circ}$ domain structure (Fig. 7(a)) is recovered. This reorientation of the $90^{\circ}$ domains is the reason why the crystals $(50 \mathrm{ml} / \mathrm{min})$ showed a smaller $P_{\mathrm{r}}$ in spite of having a large $P$ value at $E=80$ $\mathrm{kV} / \mathrm{cm}$.

The reorientation of the $90^{\circ}$ domains deteriorates the piezoelectric properties in addition to the polarization properties. Piezoelectric strain originating from inverse piezoelectric effects is defined as the deformation of crystals induced by applying $E$ application without the change in domain structure. For ferroelectric materials, piezoelectric strain tensor is defined unambiguously for the crystals with the single domain state (here, we do not consider the cooperative effect of $90^{\circ}$ domain walls in engineered domain configurations. ${ }^{21), 22)}$ ) When the reorientation of the $90^{\circ}$ domains occurs and the value of $P_{\mathrm{r}}$ decrease, effective strain induced by $E$ application becomes smaller, leading to a lower $d_{33}$. It is considered that the low $d_{33}$ values for the crystals $(50 \mathrm{ml} / \mathrm{min}$ and $100 \mathrm{ml} / \mathrm{min})$ are attributed to the reorientation of the $90^{\circ}$ domains.

It has been reported that the reorientation of the $90^{\circ}$ domains originates from the interaction between $P_{\mathrm{s}}$ and defect dipole (D) ${ }^{106), 107)}$ Figure 7 depicts the schematics of the reorientation of the $90^{\circ}$ domains, i.e., the reversible $90^{\circ}$ domain rotation, in BNTBT crystals. At intermediate temperatures in the range of $400^{\circ} \mathrm{C}$

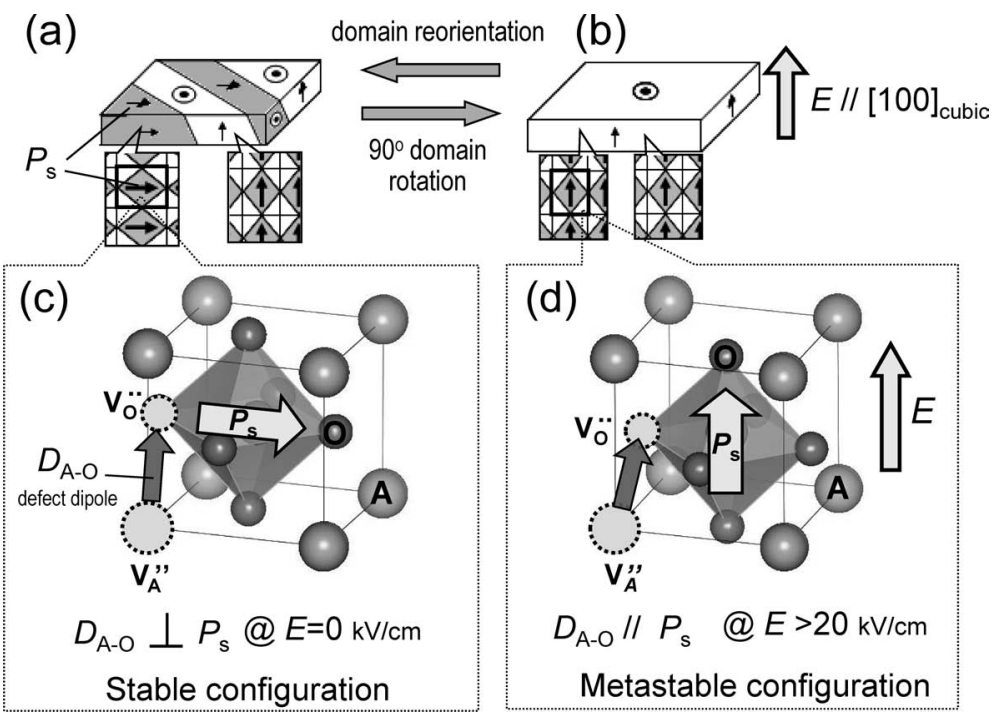

Fig. 7. Schematics of the configuration of $P_{\mathrm{S}}$ and defect dipole $\left(D_{\mathrm{A}-\mathrm{O}}\right)$ composed of $A$-site vacancy $\left(V_{\mathrm{A}}\right.$ ") and oxygen vacancy $\left(V_{\mathrm{O}}{ }^{*}\right)$ (a) before and (b) after $90^{\circ}$ domain rotation by $E$ application. Metastable single domain state $[(\mathrm{b})]$ is established only during $E$ application, and the $90^{\circ}$ domains are recovered to the initial state $[(\mathrm{a})]$ after removing $E$. 


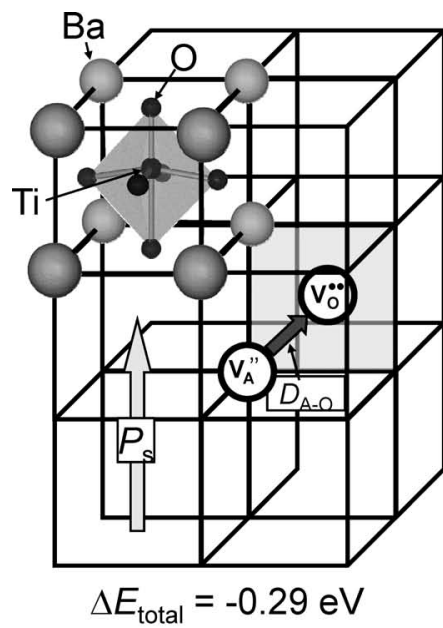

(a) $D_{\mathrm{A}-\mathrm{O}} / / P_{\mathrm{s}}$

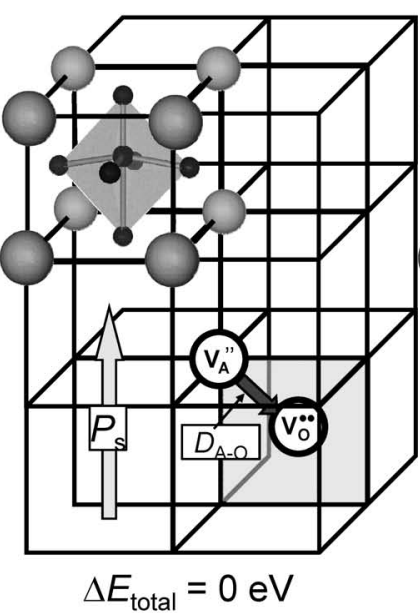

(b) $D_{\mathrm{A}-\mathrm{O}} / / P_{\mathrm{s}}$

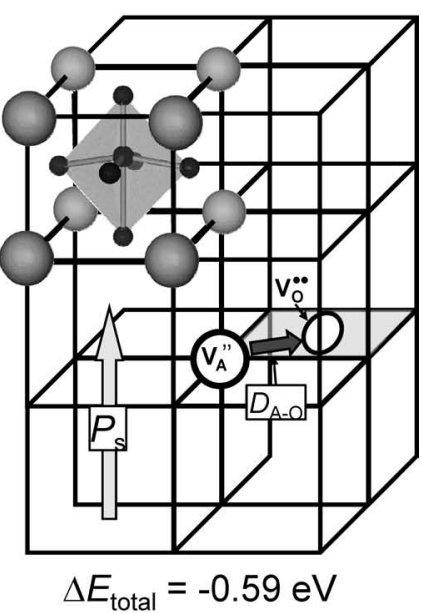

(c) $D_{\mathrm{A}-\mathrm{O}} \perp P_{\mathrm{s}}$

Fig. 8. Supercells of tetragonal $\mathrm{BaTiO}_{3}$ for $a b$ initio calculations of the interaction between spontaneous polarization $\left(P_{\mathrm{s}}\right)$ and defect dipole $\left(D_{\mathrm{A}-\mathrm{O}}\right)$ composed of A-site vacancy $\left(V_{\mathrm{A}}\right.$ ") and oxygen vacancy $\left(V_{\mathrm{O}} \cdot{ }^{*}\right)$. There are three possible configurations of $D_{\mathrm{A}-\mathrm{O}}$ and $P_{\mathrm{s}}$ : (a) $D_{\mathrm{A}-\mathrm{O}}$ parallel to $P_{\mathrm{s}}$; (b) $D_{\mathrm{A}-\mathrm{O}}$ antiparallel to $P_{\mathrm{s}}$, (c) $D_{\mathrm{A}-\mathrm{O}}$ normal to $P_{\mathrm{s}}$. Ab initio calculations show that the configuration of (c) $D_{\mathrm{A}-\mathrm{O}}$ normal to $P_{\mathrm{s}}$ leads to a lowest total energy.

to $800^{\circ} \mathrm{C}, V_{\mathrm{Bi}}{ }^{\prime \prime}$ and $V_{\mathrm{O}}{ }^{\circ}$ do not form defect dipole due to the contribution of entropy term to total free energy, and $V_{\mathrm{O}}{ }^{*}$ takes a random walk. With decreasing temperature, the defect dipoles $\left(D_{\mathrm{A}-\mathrm{O}}\right)$ composed of $V_{\mathrm{Bi}}{ }^{\prime}$ " and $V_{\mathrm{O}}{ }^{\prime}$ becomes energetically favorable to form due to the attractive interaction between them. In Fig. 7 , the vacancy at the $A$ site including $V_{\mathrm{Bi}}$ "” is expressed as $V_{\mathrm{A}}$ ".

\subsection{Ab initio calculations of the interaction between $P_{\mathrm{s}}$ and defect dipole}

To perform $a b$ initio calculations of the interaction between $P_{\mathrm{s}}$ and $D$, we have selected a model material of tetragonal $\mathrm{BaTiO}_{3}$ with $D_{\mathrm{A}-\mathrm{O}}$ composed of Ba vacancy $\left(V_{\mathrm{A}}{ }^{\prime \prime}\right)$ and $V_{\mathrm{O}}{ }^{*}$. At first, the structure optimization of tetragonal $\mathrm{BaTiO}_{3}$ with $P 4 m m$ space group was performed. The resultant structural parameters are $a$ $=0.397144 \mathrm{~nm}, c=0.408949 \mathrm{~nm}$, which quantitatively agree well with the experimental structural data. ${ }^{111)}$ A supercell with $2 a$ $\times 2 a \times 3 c$ was built up using the optimized $\mathrm{BaTiO}_{3}$, in which the $c$ axis of the supercell is set to be long to reduce ferroelectric cell-to-cell interaction.

In view of the directions of $D_{\mathrm{A}-\mathrm{O}}$ with respect to $P_{\mathrm{s}}$, there are three kinds configuration, as schematically illustrated in Fig. 8. The directions of $P_{\mathrm{s}}$ and $D$ shown in Figs. 8(a) and (b) are designated as parallel: (a) $P_{\mathrm{s}}$ parallel to $D_{\mathrm{A}-\mathrm{O}}$ and (b) $P_{\mathrm{s}}$ antiparallel to $D_{\mathrm{A}-\mathrm{O}}$. The rest depicted in Fig. $8(\mathrm{c})$ is the configuration with $P_{\mathrm{s}}$ normal to $D_{\mathrm{A}-\mathrm{O}}$. After these vacancies are created in the supercell, a higher crystal symmetry is imposed for each cell: (a) $P_{\mathrm{m}}$, (b) $P_{\mathrm{m}}$ and (c) $C_{\mathrm{m}}$. Structural optimization was again performed for all atoms with the fixed lattice parameters and then total energies $\left(E_{\text {total }}\right)$ of the optimized cell were calculated. Since the configuration of $P_{\mathrm{s}}$ antiparallel to $D_{\mathrm{A}-\mathrm{O}}$ (Fig. 8(b)) shows the highest $E_{\text {total }}$, this value is set to the standard for comparison. The configuration of $P_{\mathrm{s}}$ parallel to $D_{\mathrm{A}-\mathrm{O}}$ (Fig. 8(a)) exhibits a lower $E_{\text {total }}$ by $0.29 \mathrm{eV}\left(\Delta E_{\text {total }}=-0.29 \mathrm{eV}\right)$, which is quit reasonable in view of electrostatic interaction. Note that an $E_{\text {total }}$ of the configuration with $P_{\mathrm{s}}$ normal to $D_{\mathrm{A}-\mathrm{O}}$ (Fig. $\left.8(\mathrm{c})\right)$ becomes the smallest $\left(\Delta E_{\text {total }}\right.$ $=-0.59 \mathrm{eV})$, which indicates that this $D_{\mathrm{A}-\mathrm{O}}$ configuration with respect to $P_{\mathrm{s}}$ is the grand state for tetragonal $\mathrm{BaTiO}_{3}$.

These calculations suggest that the configuration of $D_{\mathrm{A}-\mathrm{O}}$ perpendicular to $P_{\mathrm{s}}$ (Fig. 7(c), stable configuration) is energetically preferred compared with those of $D_{\mathrm{A}-\mathrm{O}}$ parallel (Fig. 7(d)) and antiparallel to $P_{\mathrm{S}}$ (the configurations of $D_{\mathrm{A}-\mathrm{O}}$ parallel/antiparallel to $P_{\mathrm{s}}$ are metastable). After the $90^{\circ}$ domain structure is established below $T_{\mathrm{C}}, V_{\mathrm{O}}{ }^{*}$ hops into the adjacent $\mathrm{O}$ site even near room temperature ${ }^{106), 107)}$ to form the stable $D_{\mathrm{A}-\mathrm{O}}$ configuration in each $90^{\circ}$ domain (Fig. 7(c)). This redistribution of $D_{\mathrm{A}-\mathrm{O}}$ resulting from the $V 0^{*}$ hopping further stabilizes the $90^{\circ}$ domain structure. ${ }^{106), 107)}$ When $E$ is applied along the $[100]_{\text {cubic }}$ direction to the crystals with this $90^{\circ}$ domain structure, the domains with $P_{\mathrm{s}}$ normal to $E$ are rotated by $90^{\circ}$ so that the $P_{\mathrm{s}}$ vector becomes parallel to $E$. As a result, the $90^{\circ}$ domains rotate and the metastable single domain state (Figs. 7(b) and (d)) is established by $E$ application. With decreasing $E$, the reorientation of the $90^{\circ}$ domains from the metastable single domain state (Fig. 7(b)) to the multidomain state (Fig. 7(a)) occurs due to the stabilization by the interaction between $P_{\mathrm{s}}$ and $D_{\mathrm{A}-\mathrm{O}}$, because the defect configuration with $D_{\mathrm{A}-\mathrm{O}}$ normal to $P_{\mathrm{s}}$ (Fig. 7(c)) is energetically favorable compared with $D_{\mathrm{A}-\mathrm{O}}$ parallel/antiparallel to $P_{\mathrm{s}}$. It is concluded that the interaction between $P_{\mathrm{s}}$ and $D_{\mathrm{A}-\mathrm{O}}$ is the origin of the reorientation of the $90^{\circ}$ domains leading to poor polarization and piezoelectric properties observed for BNT-BT crystals.

\section{Conclusions}

To establish a guiding principle of defect control during crystal growth for obtaining high-quality Bi-based ferroelectric single crystals, we selected perovskite BNT-BT near the MPB composition as a model material. The $\mathrm{O}_{2}$-blowing method was developed for high-quality BNT-BT single crystals based on defect chemistry. The properties of leakage current, remanent polarization and piezoelectric constants were markedly improved by increasing $\mathrm{O}_{2}$-flow rate during crystal growth. The piezoelectric strain constant $\left(d_{33}\right)$ of $288 \mathrm{pm} / \mathrm{V}$ was achieved along the [100 $]_{\text {cubic }}$ direction for the crystals obtained by the $\mathrm{O}_{2}$-blowing method. The vacancies of $\mathrm{Bi}$ and $\mathrm{O}$ formed during crystal growth are shown to originate from poor properties of BNT-BT crystals. The reorientation of non- $180^{\circ}$ domains is indicated to deteriorate remanent polarization and $d_{33}$ for the crystals with high concentrations of the vacancies. $A b$ initio calculations suggest that the interaction between spontaneous polarization and defect dipole composed of 
$\mathrm{Bi}$ vacancy and $\mathrm{O}$ vacancy is the origin of the reorientation of non$180^{\circ}$ domains. The $\mathrm{O}_{2}$-blowing method is demonstrated to be effective for growing high-quality BNT-BT single crystals with low concentrations of $\mathrm{Bi}$ vacancy and $\mathrm{O}$ vacancy.

Acknowledgement This work was partly supported by Grantin-Aid for Scientific Research on Priority Areas "Novel States of Matter Induced by Frustration" (19052002) from Ministry of Education, Culture, Sports, Science and Technology.

\section{References}

1) G. H. Haertling, J. Am. Ceram. Soc., 82, 797-818 (1999).

2) J. F. Scott, C. A. Araujo, B. M. Melnick, L. D. McMillan and R. Zuleeg, J. Appl. Phys., 70, 382-388 (1991).

3) S. E. Park and T. R. Shrout, IEEE Trans. Ultrason. Ferroelectr. Freq. Control, 44, 1140-1147 (1997).

4) S. B. Park and C. T. Sun, J. Am. Ceram. Soc., 78, 1475-1480 (1995).

5) R. Ramesh, W. K. Chan, B. Wilkens, H. Gilchrist, T. Sands, J. M. Tarascon, V. G. Keramidas, D. K. Fork, J. Lee and A. Safari, Appl. Phys. Lett., 61, 1537-1539 (1992).

6) B. Noheda, J. A. Gonzalo, L. E. Cross, R. Guo, S. E. Park, D. E. Cox and G. Shirane, Phys. Rev. B, 61, 8687-8695 (2000).

7) R. Guo, L. E. Cross, S. E. Park, B. Noheda, D. E. Cox and G. Shirane, Phys. Rev. Lett., 84, 5423-5426 (2000).

8) B. H. Kim, J. W. Moon, Y. D. Song, N. Mizutani and K. Shinozaki, J. Ceram. Soc. Japan, 114, 603-606 (2006).

9) M. Kobune, Y. Maekawa, A. Mineshige, T. Yazawa and H. Nishioka, J. Ceram. Soc. Japan, 114, 241-246 (2006).

10) J. S. Park, S. J. Yang, K. I. Lee and S. G. Kang, J. Ceram. Soc. Japan, 114, 1089-1092 (2006).

11) T. Tsurumi, J. Ceram. Soc. Japan, 115, 17-22 (2007).

12) M. Aratani and H. Funakubo, Ferroelectrics, 260, 413-418 (2001).

13) K. Nagashima and H. Funakubo, Jpn. J. Appl. Phys., 39, 212-216 (2000)

14) G. Asano, T. Oikawa, H. Funakubo and K. Saito, Jpn. J. Appl. Phys., 42, L1083-L1086 (2003).

15) H. Morioka, G. Asano, T. Oikawa, H. Funakubo and K. Saito, Appl. Phys. Lett., 82, 4761-4763 (2003).

16) C. H. Lee, S. I. Lee and S. J. Kim, J. Ceram. Soc. Japan, 116, 158-162 (2008)

17) Y. Wang, K.-F. Cheung, S.-W. Or, H. Chan and H. Luo, J. Ceram. Soc. Japan, 116, 540-544 (2008).

18) H. Takahashi, Y. Numamoto, J. Tani and S. Tsurekawa, Jpn. J. Appl. Phys., 46, 7044-7047 (2007).

19) T. Karaki, K. Yan and M. Adachi, Jpn. J. Appl. Phys., 46, 7035-7038 (2007).

20) T. Karaki, K. Yan, T. Miyamoto and M. Adachi, Jpn. J. Appl. Phys., 46, L97-L98 (2007).

21) S. Wada, T. Muraishi, K. Yokoh, H. Kakemoto and T. Tsurumi, J. Korean Phys. Soc., 51, 874-877 (2007).

22) S. Wada, T. Muraishi, K. Yokoh, K. Yako, H. Kamemoto and T. Tsurumi, Ferroelectrics, 355, 37-49 (2007).

23) S. Wada, K. Takeda, T. Muraishi, H. Kakemoto, T. Tsurum and T. Kimura, Jpn. J. Appl. Phys., 46, 7039-7043 (2007).

24) T. Takenaka and K. Sakata, Ferroelectrics, 95, 153-156 (1989).

25) T. Takenaka, K. Sakata and K. Toda, Ferroelectrics, 106, 375-380 (1990).

26) T. Takenaka, K. Maruyama and K. Sakata, Jpn. J. Appl. Phys., 30, 2236-2239 (1991).

27) H. Nagata, M. Yoshida, Y. Makiuchi and T. Takenaka, Jpn. J. Appl. Phys., 42, 7401-7403 (2003).

28) A. Sasaki, T. Chiba, Y. Mamiya and E. Otsuki, Jpn. J. Appl. Phys., 38, 5564-5567 (1999).
29) A. Herabut and A. Safari, J. Am. Ceram. Soc., 80, 2954-2958 (1997).

30) S. B. Vakhrushev, V. A. Isupov, B. E. Kvyatkovsky, N. M. Okuneva, I. P. Pronin, G. A. Smolensky and P. P. Syrnikov, Ferroelectrics, 63, 153-160 (1985).

31) Z. W. Chen, A. Shui, Z. Y. Lu and P. G. Liu, J. Ceram. Soc. Japan, 114, 857-860 (2006).

32) S. Tashiro and K. Ishii, J. Ceram. Soc. Japan, 114, 386-391 (2006).

33) Y. Saito, H. Takao, T. Tani, T. Nonoyama, K. Takatori, T. Homma, T. Nagaya and M. Nakamura, Nature, 432, 84-87 (2004).

34) Y. P. Guo, K. Kakimoto and H. Ohsato, Appl. Phys. Lett., 85, 4121-4123 (2004).

35) Y. Kizaki, Y. Noguchi and M. Miyayama, Appl. Phys. Lett., 89, 142910 (2006).

36) E. Z. Li, H. Kakemoto, S. Wada and T. Tsurumi, J. Ceram. Soc. Japan, 115, 250-253 (2007).

37) C. Pithan, Y. Shiratori, A. Magrez, S. B. Mi, J. Dornseiffer and R. Waser, J. Ceram. Soc. Japan, 114, 995-1000 (2006).

38) T. Tani, J. Ceram. Soc. Japan, 114, 363-370 (2006).

39) Y. Sun, D. Xiao, L. Wu, D. Lin, J. Zhu, P. Yu, X. Li, Y. Wang, Y. Li, Y. Lin, Y. Zhuang and Q. Wei, J. Ceram. Soc. Japan, 116, 536-539 (2008).

$40)$ C. A. Paz de Araujo, J. D. Cuchiaro, L. D. McMillan, M. C. Scott and J. F. Scott, Nature, 374, 627-629 (1995).

41) Y. Noguchi, M. Miyayama, K. Oikawa and T. Kamiyama, $J$. Appl. Phys., 95, 4261-4266 (2004).

42) Y. Noguchi, M. Miyayama, K. Oikawa, T. Kamiyama, M. Osada and M. Kakihana, Jpn. J. Appl. Phys., 41, 7062-7075 (2002).

43) H. Funakubo, M. Mitsuya, N. Nukaga and K. Ishikawa, Integrated Ferroelectrics, 30, 225-234 (2000).

44) F. Nagata, T. Takahashi, Y. Yano and T. Takenaka, Ferroelectrics, 261, 883-888 (2001).

45) H. Mitsumata and T. Mori, J. Ceram. Soc. Japan, 114, 705708 (2006).

46) Y. Idemoto, T. Takahashi, N. Koura, J. W. Richardson and C. K. Loong, J. Ceram. Soc. Japan, 114, 630-637 (2006).

47) Y. Idemoto and S. Taniyama, J. Ceram. Soc. Japan, 115, 960-966 (2007).

48) S. E. Cummins and L. E. Cross, Appl. Phys. Lett., 10, 14-16 (1967).

49) S. E. Cummins and L. E. Cross, J. Appl. Phys., 39, 22682274 (1968)

50) T. Takenaka and K. Sakata, Ferroelectrics, 19, 172-172 (1978).

51) T. Takenaka and K. Sakata, Jpn. J. Appl. Phys., 19, 31-39 (1980).

52) T. Takenaka, J. Ceram. Soc. Japan, 110, 215-224 (2002).

53) H. Nagata, J. Ceram. Soc. Japan, 116, 271-277 (2008).

54) A. Watanabe, T. Fukui, K. Nogi, Y. Kizaki, Y. Noguchi and M. Miyayama, J. Ceram. Soc. Japan, 114, 97-101 (2006).

55) D. Y. Lu and M. Toda, J. Ceram. Soc. Japan, 114, 612-619 (2006).

56) H. Ogawa, M. Kimura, A. Ando and Y. Sakabe, Jpn. J. Appl. Phys., 40, 5715-5718 (2001).

57) T. Takeuchi, T. Tani and Y. Saito, Jpn. J. Appl. Phys., 39, 5577-5580 (2000).

58) C. Moure, L. Lascano, J. Tartaj and P. Duran, Ceram. Int., 29, 91-97 (2003).

59) H. X. Yan, H. T. Zhang, M. J. Reece and X. L. Dong, Appl. Phys. Lett., 87, 082911 (2005).

60) K. Kato, K. Suzuki, K. Nishizawa and T. Miki, Appl. Phys. Lett., 78, 1119-1121 (2001).

61) K. Kato, D. S. Fu, K. Suzuki, K. Tanaka, K. Nishizawa and T. Miki, Appl. Phys. Lett., 84, 3771-3773 (2004).

62) K. Kato, K. Suzuki, D. S. Fu, K. Nishizawa and T. Miki, Appl. Phys. Lett., 81, 3227-3229 (2002). 
63) T. Kimura, J. Ceram. Soc. Japan, 114, 15-25 (2006).

64) S. Zhang, R. Xia, H. Hao, H. Liu and T. R. Shrout, Appl. Phys. Lett., 92, 152904 (2008).

65) Y. Watanabe, Y. Hiruma, H. Nagata and T. Takenaka, Ferroelectrics, 358, 1021-1025 (2007).

66) K. Yoshii, Y. Hiruma, H. Nagata and T. Takenaka, Jpn. J. Appl. Phys., 45, 4493-4496 (2006).

67) G. O. Jones, J. Kreisel, V. Jennings, M. A. Geday, P. A. Thomas and A. M. Glazer, Ferroelectrics, 270, 1377-1382 (2002).

68) G. O. Jones and P. A. Thomas, Acta Crystallogr. Sect. BStruct. Commun., 58, 168-178 (2002).

69) D. L. West and D. A. Payne, J. Am. Ceram. Soc., 86, 769774 (2003).

70) D. L. West and D. A. Payne, J. Am. Ceram. Soc., 86, 192194 (2003).

71) H. W. Cheng, X. J. Zhang, S. T. Zhang, Y. Feng, Y. F. Chen, Z. G. Liu and G. X. Cheng, Appl. Phys. Lett., 85, 2319-2321 (2004).

72) X. X. Wang, K. W. Kwok, X. G. Tang, H. L. W. Chan and C. L. Choy, Solid State Commun., 129, 319-323 (2004).

73) H. D. Li, C. D. Feng and W. L. Yao, Mater. Lett., 58, 1194 1198 (2004).

74) X. X. Wang, S. W. Or, X. G. Tang, H. L. W. Chan, P. K. Choy and P. C. K. Liu, Solid State Commun., 134, 659-663 (2005).

$75)$ B. J. Chu, J. H. Cho, Y. H. Lee, B. K. Kim and D. R. Chen, J. Ceram. Process. Res., 3, 231-234 (2002).

76) X. Y. Huang, C. H. Gao, Z. G. Chen and H. P. Liu, Journal of Rare Earths, 24, 321-324 (2006).

77) T. Kimura, T. Takahashi, T. Tani and Y. Saito, Ceram. Int., 30, 1161-1167 (2004).

78) D. S. Lee, S. J. Jeong, E. C. Park and J. S. Song, J. Electroceram., 17, 505-508 (2006).

79) J. S. Song, S. J. Jeong, I. S. Kim, D. S. Lee and E. C. Park, Ferroelectrics, 338, 1419-1424 (2006).

80) W. B. Wu, K. Fumoto, Y. Oishi, M. Okuyama and Y. Hamakawa, Jpn. J. Appl. Phys., 35, 1560-1563 (1996).

81) T. Watanabe, A. Saiki, K. Saito and H. Funakubo, J. Appl. Phys., 89, 3934-3938 (2001).

82) H. Irie, H. Saito, S. Ohkoshi and K. Hashimoto, Adv. Mater., 17, 491-494 (2005).

83) T. Watanabe and H. Funakubo, J. Appl. Phys., 100, 051602 (2006).

84) J. F. Scott and M. Dawber, Appl. Phys. Lett., 76, 3801-3803 (2000).

85) L. X. He and D. Vanderbilt, Phys. Rev. B, 68, 134103 (2003).

86) M. Dawber and J. F. Scott, Appl. Phys. Lett., 76, 1060-1062 (2000).
87) B. H. Park, B. S. Kang, S. D. Bu, T. W. Noh, J. Lee and W. Jo, Nature, 401, 682-684 (1999).

88) A. Snedden, P. Lightfoot, T. Dinges and M. S. Islam, J. Solid State Chem., 177, 3660-3665 (2004).

89) Y. J. Noguchi, I. Miwa, Y. Goshima and M. Miyayama, Jpn. J. Appl. Phys., 39, L1259-L1262 (2000).

90) Y. Noguchi and M. Miyayama, Appl. Phys. Lett., 78, 19031905 (2001).

91) T. Goto, Y. Noguchi, M. Soga and M. Miyayama, Mater. Res. Bull., 40, 1044-1051 (2005).

92) Y. Noguchi, T. Matsumoto and M. Miyayama, Key Eng. Mater., 320, 19-22 (2006).

93) Y. Kitanaka, S. Katayama, Y. Noguchi and M. Miyayama, Jpn. J. Appl. Phys., 46, 7028-7030 (2007).

94) Y. Kitanaka, Y. Noguchi and M. Miyayama, Appl. Phys. Lett., 90, 202904 (2007).

95) K. Yamamoto, Y. Kitanaka, M. Suzuki, M. Miyayama, Y. Noguchi, C. Moriyoshi and Y. Kuroiwa, Appl. Phys. Lett., 91, 162909 (2007).

96) Z. G. Ye, Curr. Opin. Solid State Mat. Sci., 6, 35-44 (2002).

97) X. J. Yi, H. C. Chen, W. W. Cao, M. L. Zhao, D. M. Yang, G. P. Ma, C. H. Yang and J. R. Han, J. Cryst. Growth, 281, 364-369 (2005).

98) S. Yoshimura, Y. Noguchi and M. Miyayama, Key Eng. Mater., 320, 35-38 (2006).

99) P. Hohenberg and W. Kohn, Phys. Rev., 136, 864-871 (1964).

100) W. Kohn and L. J. Sham, Phys. Rev., 140, 1133-1138 (1965).

101) J. P. Perdew, K. Burke and Y. Wang, Phys. Rev. B, 54, 16533-16539 (1996).

102) J. P. Perdew, K. Burke and M. Ernzerhof, Phys. Rev. Lett., 77, 3865-3868 (1996).

103) P. E. Blochl, Phys. Rev. B, 50, 17953-17979 (1994).

104) G. Kresse and J. Furthmuller, Phys. Rev. B, 54, 11169-11186 (1996).

105) G. Kresse and J. Furthmuller, Comput. Mater. Sci., 6, 15-50 (1996).

106) X. B. Ren, Nature Materials, 3, 91-94 (2004).

107) L. X. Zhang, W. Chen and X. Ren, Appl. Phys. Lett., 85, 5658-5660 (2004).

108) Y. Noguchi, T. Matsumoto and M. Miyayama, Jpn. J. Appl. Phys., 44, L570-L572 (2005).

109) Y. Noguchi, M. Soga, M. Takahashi and M. Miyayama, Jpn. J. Appl. Phys., 44, 6998-7002 (2005).

110) F. Izumi and K. Momma, Solid State Phenom., 130, 15-20 (2007).

111) Y. Kuroiwa, S. Aoyagi and A. Sawada, Phys. Rev. Lett., 87, 217601-217604 (2001). 